http://lppm.upiyptk.ac.id/ojs3/index.php/MAJALAHILMIAH/index

\title{
ANALISA DESAIN KOMUNIKASI VISUAL UNTUK MEMBANGUN E-BRANDING UKM CATERING KOTA PADANG DENGAN KONSEP CRM (Customer Relationship Management)
}

\author{
Mutiana Pratiwi', Widia Marta ${ }^{2}$ \\ Universitas Putra Indonesia YPTK Padang \\ E-mail: mutianapratiwi26@gmail.com \\ E-mail: widia1302@gmail.com
}

\begin{abstract}
ABSTRAK
Usaha mikro kecil mengengah merupakan suatu bidang usaha yang sangat membantu dalam berbagai aspek perekonomian indonesia. Di kota Padang memiliki berbagai macam jenis bisnis UKM. Satu diantaranya adalah Catering. Perkembangan usaha catering dikota ini sangat pesat karena banyaknya minat masyarakat menggunakan jasa tersebut. Akibatnya muncul persaingan antar usaha yang memperlihatkan dampak yang cukup signifikan terhadap usaha catering sehingga masing-masing usaha tersebut harus mampu untuk menciptakan pasar mereka sendiri dengan cara menciptakan Brand terhadap usaha catering yang mereka miliki. Penelitian ini dilakukan untuk melakukan analisa desain komunikasi visual untuk menciptakan E-Branding dengan konsep CRM ( Customer Relationship Management) . Hasil dari penelitian ini adalah terciptanya E-Branding Catering, yang memiliki manfaat sebagai bentuk aktualisasi karakter usaha UKM Catering serta menunjang pemasaran dan meningkatkan daya saing.
\end{abstract}

Kata Kunci : Brand, CRM, Catering, UKM, E-Branding

\section{PENDAHULUAN}

Customer Relationship Management (CRM) adalah suatu teknologi informasi akan mampu mengatasi masalah, karena tujuan CRM adalah mendapatkan inti konsep pelanggan dan meletakkannya dalam kerangka aplikasi pemanfaatan teknologi informasi berbasis E-Commerce. Pada penelitian (Ishak Kholil 2012) membahas tentang aplikasi E-CRM dalam meningkatkan daya saing usaha kecil menengah, dan menurut hasil penelitian tersebut CRM dapat membantu UKM mengembangkan produk baru berdasarkan pengetahuan yang lengkap tentang keinginan pelanggan, dinamika pasar dan pesaing. Penelitian ini dilakukan untuk mengembangkan perangkat lunak CRM pada usaha mikro kecil dan menengah. Masih sedikit UKM yang telah menerapkan CRM ini walaupun sudah banyak UKM menyadari pemanfaatan teknologi informasi menjadi suatu keharusan yang tidak dapat dihindari oleh setiap usaha yang ingin menempatkan dirinya pada posisi paling depan dalam suatu industri.

Usaha yang perkembangannya paling pesat saat ini adalah catering.Banyak masyarakat membutuhkan usaha jasa ini.Usaha catering adalah istilah umum untuk wirausaha yang melayani pemesanan berbagai macam masakan dan minuman yang melibatkan perlengkapan untuk kebutuhan acara pesta maupun instansi yang disiapkan pada waktu dan tempat tertentu.Meningkatnya permintaan atas jasa catering menyebabkan munculnya banyak UKM catering baru yang terjun ke usaha ini sehingga membuat persaingan menjadi semakin ketat.Pada forum ASEAN Economic Community (AEC) padatahun 2007, UKMdituntut untuk melakukan perubahan gunameningkatkan daya saingnya agar dapat terusberjalan dan berkembang. Salah satunya adalah dengan cara menggunakan teknologi informasi(TI). Menurut Penelitian (Muhammad Rozahi Istambul, 2010) dalam judul pandangan pengelolaan sumber daya perusahaan menggunakan teknologi informasi untuk meningkatkan daya saing usaha kecil menengah bahwa penggunaan TI dapat meningkatkantransformasi bisnis melalui 


\section{MAJALAH ILMIAH}

http://lppm.upiyptk.ac.id/ojs3/index.php/MAJALAHILMIAH/index

kecepatan,ketepatan dan efisiensi pertukaran informasidalam jumlah yang besar.Hal ini membuat UKM-UKM catering mengalami tantangan yang lebih berat untuk mampu mempertahaknkan keberadaannya dan juga mengembangkan usahanya.Untuk usaha kecil dan menengah (UKM) seperti catering di kota padang sangatlah penting menciptakan sebuah brand agar lebih dikenal oleh masyarakat. Penciptaan E-Branding ini memiliki manfaat sebagai aktualisasi karakter bagi UKM catering. Maka dari itu sangat dibutuhkan.

\section{METODE PENELITIAN}

\section{Pendahuluan}

Pada bab ini, diuraikan keterangan kerja penelitian. Adapun penelitian ini diawali dengan mengidentifikasi masalah branding dengan Analisa Desain Komunikasi Visual dengan konsep CRM (Customer Relationship Management)yang membantu memberikan pengaruh besar terhadap daya beli pelanggan.

Tujuan penelitian yakni Memahami tahapan dalam membranding usaha dan Membangun aplikasi ebranding UMKM Catering dengan konsep CRM.

Pada tahap berikutnya yakni pengumpulan data dilakukan dengan observasi secara langsung.

\section{Kerangka Penelitian}

Kerangka kerja penelitian ini dilakukan dan dilaksanakan dengan cara sistematik sebagai pedoman peneliti dalam melaksanakan penelitian agar hasil yang dicapai tidak menyimpang dari tujuan yang telah ditetapkan sebelumnya. Kerangka kerja penelitian ini merupakan langkah-langkah yang akan dilakukan dalam rangka menyelesaikan masalah yang akan dibahas.

Kerangka kerja dalam melakukan penelitian ini adalah sebagai berikut :

\begin{tabular}{|c|c|}
\hline Memulai Penelitian & Identifikasi Masalah \\
\hline & Batasan Masalah \\
\hline & Perumusan Masalah \\
\hline Menganalisa Metodologi & Paper Pendukung \\
\hline \multirow[b]{2}{*}{ Menganalisa Data } & Teori Pendukung \\
\hline & Pengumpulan Data \\
\hline & Pengelompokan Data \\
\hline & Pengelolaan Data \\
\hline Menganalisa Sistem & Konsep CRM \\
\hline & Perancangan Brand \\
\hline & E-Branding \\
\hline Mengimplementasi & Instal Software \\
\hline & Konfigurasi Software \\
\hline \multirow{2}{*}{ Mensintesa Hasil } & Hosting Software \\
\hline & Validasi Hasil \\
\hline Menyimpulkan & Pengujian Hasil \\
\hline
\end{tabular}




\section{MAJALAH ILMIAH}

http://lppm.upiyptk.ac.id/ojs3/index.php/MAJALAHILMIAH/index

\section{Gambar 4.1 Kerangka Kerja Penelitian}

Pembahasan ini berisi penjelasan tentang kerangka kerja penelitian berdasarkan Gambar 4.1.

1. Memulai Penelitian

Pada tahap ini dilakukan identifikasi masalah yang bertujuan untuk mengidentifikasikan masalah yang akan diteliti,batasan masalah bertujuan untuk mendapatkan hasil penelitian yang baik dan terarah perlu dilakukan beberapa pembatasan masalah agar penyusunan tugas akhir ini tidak menyimpang dari tujuan yang hendak di capai,perumusan masalah bertujuan untuk menjelaskan garis besar permasalahan yang dihadapi dalam penelitian.

\section{Menganalisa Metodologi}

Pada tahap ini dilakukan analisa terhadap metodologi yang digunakan meliputi bahan pendukung dan teori pendukung dan hal-hal lain diperlukan dalam menyelesaikan penelitian.

\section{Menganalisa Data}

Pada tahap ini dilakukan studi pustaka yang bertujuan untuk mengetahui metode apa yang akan digunakan untuk menyelesaikan permasalahan yang akan diteliti yang nantinya menjadi referensi kuat bagi peneliti dalam menerapkan suatu metode yang digunakan. Dalam pelaksanaan penelitian ini dilakukan pengumpulan data untuk lebih mengetahui sistem yang diteliti .Pengumpulan data dilakukan secara langsung pada Family Catering Padang. Pengumpulan data juga dilakukan melalui internet.

\section{Menganalisa Sistem}

Pada tahap ini dilakukan penganalisaan terhadap usaha catering dengan konsep CRM setelah itu proses pembuatan brand catering dan tahap akhir pembuatan e-branding.

5. Mengimplementasikan software

Tahap ini peneliti menggunakan konsep CRM dan menggabungkan E-branding dengan teknologi informasi

6. Kesimpulan

Di mana pada tahap ini dilakukan penyempurnaan sistem, setelah dilakukan pengujian baik pengujian aplikasi dan pengujian data secara keseluruhan sehingga terjadinya suatu pemrosesan data secara cepat dan tepat di dalam sistem yang dirancang.

\section{PEMBAHASAN}

\section{Konsep Perancangan}

Logo merupakan hal yang sangat penting untuk memperkenalkan atau mempromosikan sebuah perusahaan, produk dan jasa ke lingkungan luas dalam hal ini adalah masyarakat ( audience ). Logo merupakan sebuah pencerminan atau citra dari identitas sebuah perusahaan ataupun per individu. Logo dapat memberi sebuah gambaran ( visual ) tentang apa yang dikerjakan oleh seseorang ataupun sebuah perusahaan. Dengan dibantu adanya sebuah logo dapat membuat masyarakat ( audience) lebih mudah mengingat sebuah perusahaan dan produk atau jasa apa saja yang di sediakanya.Dalam proses perancangan logo family catering menggunakan konsep simple dengan konsep masakan rumahan dan menggunakan fungsi logo yaitu logo gram dan type, logo gram menggukan gambar atau icon dari sebuah ide dari usaha catering dan logo type logo yang memakai kata atau nama dari family catering. 


\section{MAJALAH ILMIAH}

http://lppm.upiyptk.ac.id/ojs3/index.php/MAJALAHILMIAH/index

Konsep desain logo family catering menggunakan unsur dari visual peralatan alat dapur yaitu panci, piring, sendok dan garpu karena mencitrakan hidanga dan sajian. Keseluruhan unsur-unsur visual lainnya akan disatukan dengan teknik layout yang sederhana namun tetap mencerminkan kesan yang sesuai dengan identitas perusahaan.

\section{Pra desain}

Dalam melakukan sebuah desain logo family catering ada beberapa elemen-elemen yang digunakan dalam desain logo family catering.

\section{Tipografi}

Tipografi yang akan digunakan adalah huruf ( font) yang berkesan tegas dan mudah dibaca dan terlihat simple. Jenis tipografi yang akan digunakan dalam perancangan logo Klinik family catering adalah huruf yang tingkat kenyamanan dalam membacanya sangat baik, yang akan nyaman dilihat oleh audience. Berikut beberapa alternatif tipografi.

\section{a. ABCDEFGHIJKLMNOPQRSTUVWQYZ}

Abcdefghijklmnopqrstuvwqyz

0123456789 ( Lithos pro regular ) Terpilih

\section{b. ABCDEFGHIJKLMNOPQRSTUVWQYZ}

\section{Abcdefghijklmnopqrstuvwqyz \\ 0123456789 ( Lithos pro regular ) Terpilih}

Tipografi ( Lithos Pro Regular ) dipilih untuk latter mark pada logo family catering terlihat kesanya kekeluargaan, kesederhaan dan berkesan ketegasan yang akan digunakan sebagai logo family catering.

\section{Warna}

Dalam desain logo family catering, warna yang akan digunakan adalah warna yang diambil dari konsep warna Marawa (bendera Minangkabau) diartikan bahwa family catering ini berasal dari Minangkabau yaitu di Padang Sumatera Barat yang dapat menimbulkan kesan mewah dan simple (sederhana ). Dan warna yang dipilih juga harus sesuai dengan konsep perancangan family catering.

Warna abu-abu (silver). Perak adalah warna yang menunjukan atau menampilkan kesan sesuai dengan karakter peralatan alat dapur yang dipakai yaitu panci, piring, sendok, garpu yang memberikan sifanya melayani. Oleh karena itu warna ini biasanya terlihat sangat mahal dan menimbulkan efek mewah atau berkelas bagi mata yang melihatnnya.

Warna fres ( hijau ) alami, dapat memberikan dan menyajikan makanan yang sehat untuk masayarakat dan memiliki sifat jiwa mudayang akan memberikan pelayanan di setiap pelanggan yang menggunakan jasa dari family catering ini. 


\section{MAJALAH ILMIAH}

http://lppm.upiyptk.ac.id/ojs3/index.php/MAJALAHILMIAH/index

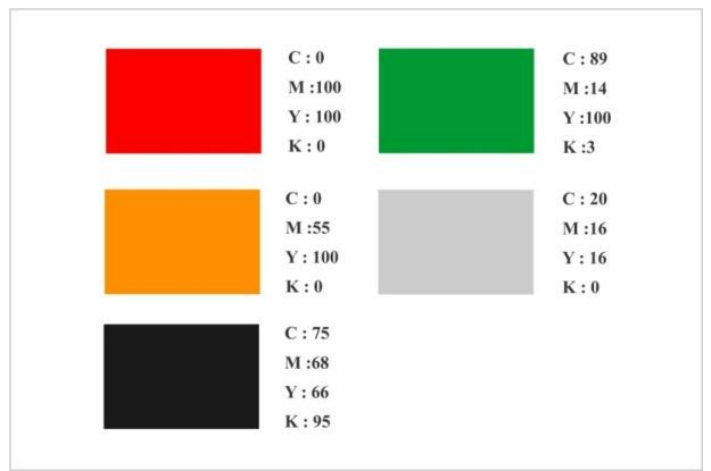

\section{Pembahasan Desain Logo}

Perancangan logo family catering merupakan gambaran atau wajah dari identitas suatu perusahaan. Dalam lingkungan bisnis yang begitu luas, tidak ada hal yang dapat membantu sebuah perusahaan atau produk terlihat lebih menonjol dibanding perusahaan dan produk lainnya selain logo. Logo adalah bagian penting dari pengakuan merek. Melalui kegiatan pemasaran lainnya untuk memprkuat seperti iklan, konsumen mulai mengasosiasikan logo dengan perusahaan. Pengenalan masyarakat terhadap logo bukanlah pekerjaan mudah, itu sebabnya logo memiliki makna dan karakteristik tersendiri, dan bisa saja mengalami perubahaan. Logo family catering ini didesain sesuai dengan USP ( unique selling proposion ) yaitu, menggunakan peralatan alat dapur yang dapat memberikan pelayanan dengan keramahan dalam menyajikan makanan.

Dalam desain logo family catering dilakukan pendekatan visual logo dengan tujuan mendapat konsep visual logo, yaitu :

\section{a. Jenis karakteristik logo}

Dalam perancangan logo family catering jenis logo yang digunakan adalah picture mark dan latter mark, yaitu elemen gambar dan tulisan digabungkan dalam sebuah kontruksi namun tidak saling berbauran. Picture mark yang akan dirancang berbentuk karakter visual abstrak yang akan berhubungan dan di sesuaikan dengan karakter perusahaan. Logo jenis ini dapat menimbulkan beraneka kesan, yang dipengaruhi oleh daya pemahaman konsumen. Ini terjadi karena bentuk visual logo yang abstrak. Sedangkan letter mark digunakan sebagai penjelas makna dari gambaran logo abstrak.

\section{b. Inventaris data visual}

Inventaris data visual perancangan logo diambil dari USP ( unique selling proposion ) konsep logo yaitu menggunakan panci salah satu peralatan dapur untuk menyajikan makanan juga mengambarkan bahwa makanan siap untuk disajikan dengan tujuan memudahkan perancang dalam mengeksplorasi bentuk sketsa logo.

1). Panci

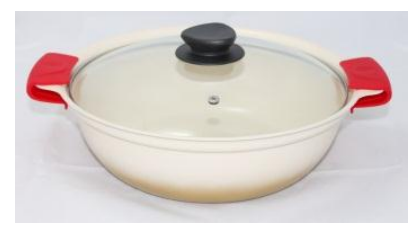




\section{MAJALAH ILMIAH}

http://lppm.upiyptk.ac.id/ojs3/index.php/MAJALAHILMIAH/index

Panci merupakan alat masak yang mampu mengahasilkan makanan yang sehat karena kandungan nutrisi makanan maupun rasanya tetap terjaga. Manfaat dan kegunaan panci bisa dirasakan oleh pemasak pemula ataupun yang sudah berpengalaman. Konsep ide dari desain visual atau icon dari alat dapur yaitu panci karena panci menggunakan alat masak yang bisa serba guna, lebih aman, simple, cepat dan bersih.

\section{2). Piring}

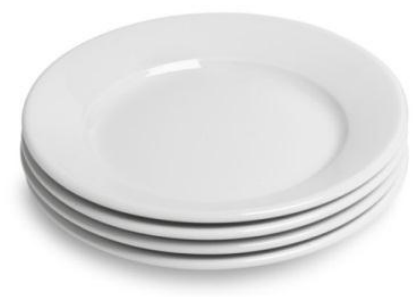

Konsep desain logo family catering visual piring adalah alat makan yang berbentuk datar dan juga ada yang sedikit cekung, di mana makanan untuk disajjkan, terbuat dari kaca, rotan, porselen, batu, plastik, piring digunakan untuk makan siap disajikan dari family catering.

3). Konsep ide asap adalah salah satu cara memasak, memberi aroma, atau proses pengawetan makanan, visual asap digunakan dalam desain logo memberikan makna bahwa makanan yang siap disajikan masih panas dan siap untuk dinikmati oleh masyarakat.

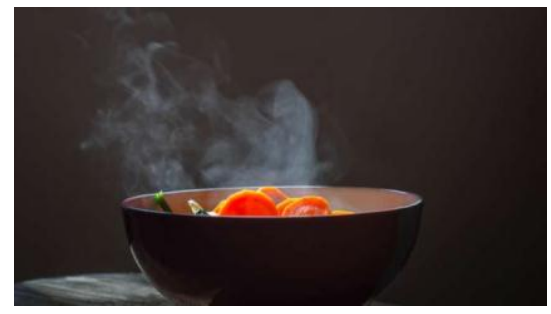

Dari semua inventaris data visual yang di dapat dilakukan stilisasi atau penyederhanaan bentuk. Gambar disederhanakan hingga berbentuk visual abstrak, namun memiliki makna berdasarkan konsep logo yang dapat memperlihatkan image atau mempersentasikan family catring.

\section{Visualisasi}

\section{a. Layout Eksekusi}

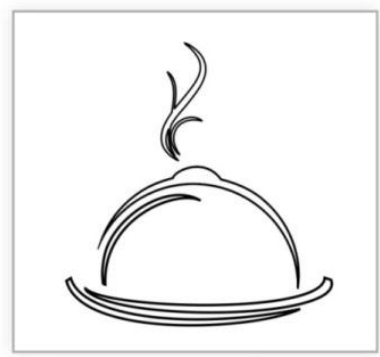

Alternatif 1

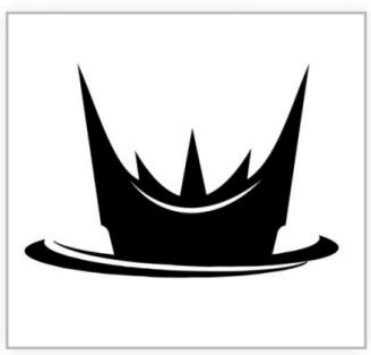

Alternatif 2

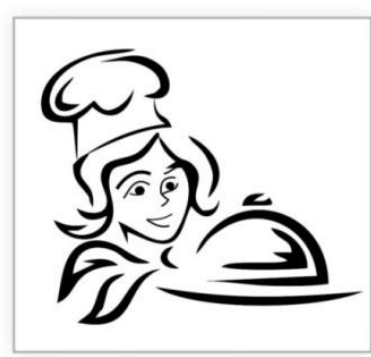

Alternatif 3

\section{b. Eksekutif alternatif Desain Logo}




\section{MAJALAH ILMIAH}

http://lppm.upiyptk.ac.id/ojs3/index.php/MAJALAHILMIAH/index

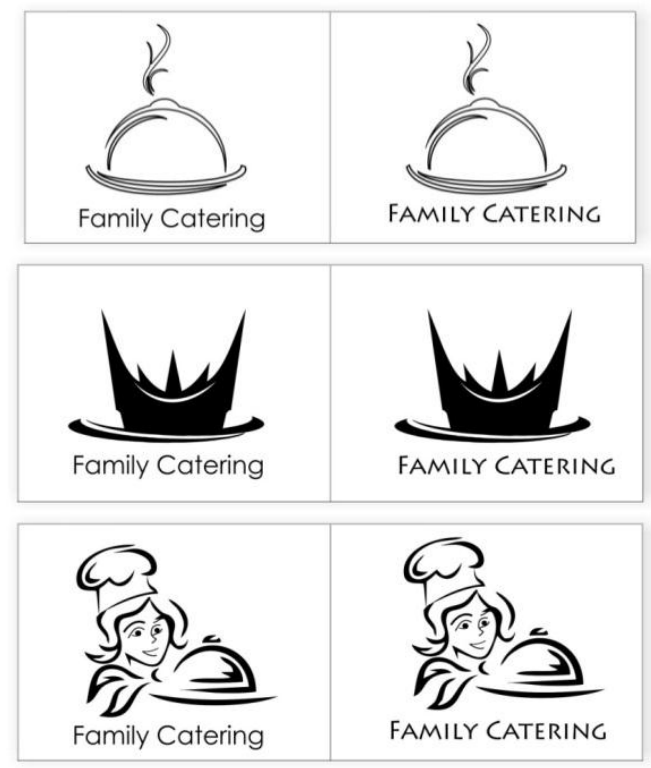

Alternatif desain logo

c. Layout Desain Komprehensif Logo

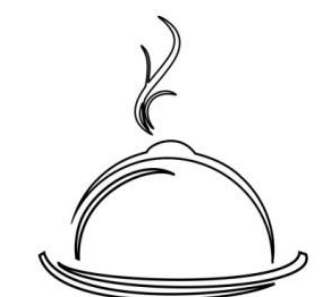

FAMILY CATERING

Alternatif 1 (Terpilih )

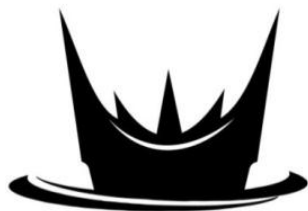

FAMILY CATERING

Alternatif 2

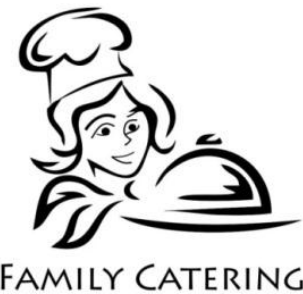

Alternatif 3

\section{d. Final Logo}

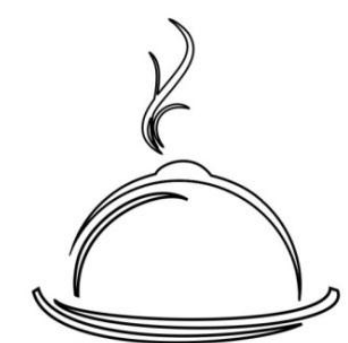

FAMILY CATERING 


\section{MAJALAH ILMIAH}

http://lppm.upiyptk.ac.id/ojs3/index.php/MAJALAHILMIAH/index

Final logo

\section{e. Final Logo Full Colour}

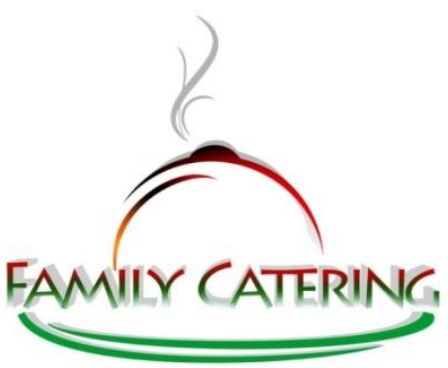

Final logo warna

\section{f. Deskripsi Logo}

Final logo yang terpilih merupakan sebuah desain yang telah mencapai konsep dan identitas dari family catering. Penggunaan bentuk logo yang menggunakan bentuk picture mark dan latter mark, dan juga bentuk visual logo yang abstrak telah sesuai dengan konsep rancangan logo yang telah dibahas.

Rancangan logo ini menampilkan kesan kesederhanaan dan juga terlihat simpel. Semua filosofi dan keunikan dari family catering sudah tergambarkan ke rancangan logo ini. Logo terbagi atas 3 bentuk yang digabungkan, yaitu.

\section{g. Grid System}




\section{MAJALAH ILMIAH}

http://lppm.upiyptk.ac.id/ojs3/index.php/MAJALAHILMIAH/index

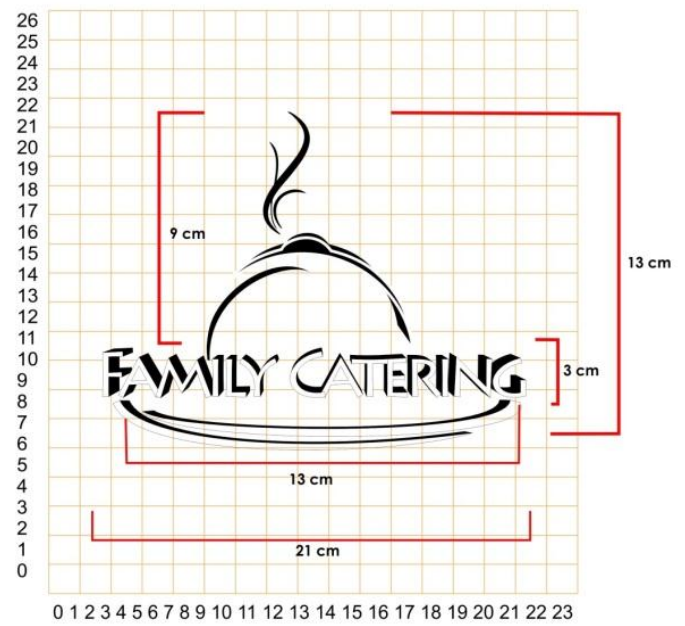

\section{h. Art Work Black and White}
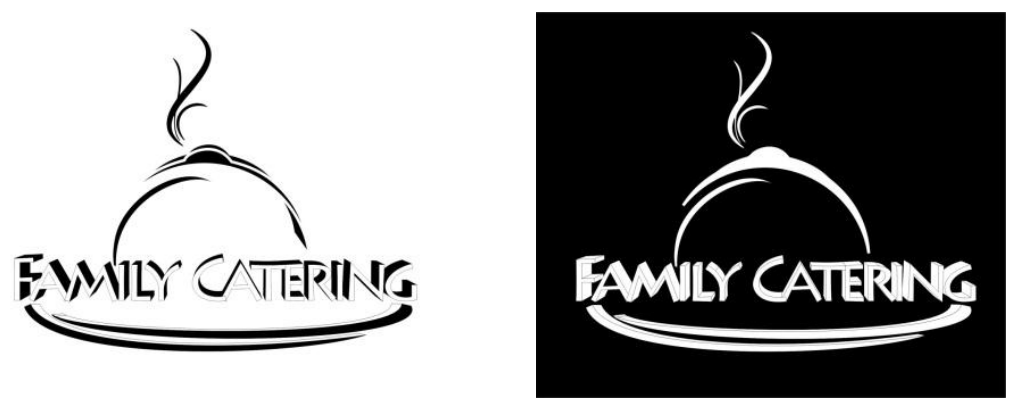

\section{KESIMPULAN}

Logo dalam jenis media aplikasi sebagai media promosi kepada masyarakat menggunakan prinsip dan unsur desain untuk menghasilkan desain yang sempurna. Disamping itu juga melakukan observasi, beberapa analisis, dan proses berkarya untuk menghasilkan desain yang baik dan efektif. Secara umum, desain logo dan aplikasinya tercipta sebagai identitas family catering sekaligus sebagai media promosi family catering kepada masyarakat untuk mendapatkan citra yang lebih baik lagi agar lebih dikenal oleh masyarakta kota Padang dan Sumatera Barat untuk menambah minat masyarakat terhadap usaha dalam bidang catering. Selain itu, logo adalah identitas diri untuk membedakannya dengan yang lain dan tanda kepemilikan untuk membedakan milik usaha walaupun bergerak di bidang yang sama. Kemudian aplikasi family catering sebagai alat memvisualkan citra usaha family catering kepada khalayak ramai bahwa usaha family catering yang ada dikota Padang sudah mempunyai cita sendiri. 


\section{MAJALAH ILMIAH}

http://lppm.upiyptk.ac.id/ojs3/index.php/MAJALAHILMIAH/index

Pemanfaatan teknologi informasi berbasis E-Commerce dalam meningkatkan daya saing usaha kecil menengah bahwa penggunaan TI dapat meningkatkan transformasi bisnis melalui kecepatan,ketepatan dan efisiensi pertukaran informasi dalam jumlah yang besar. .Untuk usaha kecil dan menengah (UKM) seperti catering di kota Padang sangatlah penting menciptakan sebuah brand agar lebih dikenal oleh masyarakat. Penciptaan E-Branding ini memiliki manfaat sebagai aktualisasi karakter bagi UKM catering dengan adanya sebuah brand dari family catering ini dapat dikenal oleh masyarak luas dan meningkatkan minat masyarakat untuk menggunakan jasa catering dari family catering yang ada dikota Padang.

\section{DAFTAR PUSTAKA}

[1] Alfin Samir, Dwi Larso (2011) "Identifikasi Faktor-Faktor yang Mempengaruhi Kinerja UKM Catering di Kota Bandung” Vol. 10(2), Jurnal Manajemen

[2] Istambul MR (2010) "Pandangan Pengelolaan Sumber Daya PerusahkanMenggunakan Teknologi Informasi UntukMeningkatkan Daya Saing Usaha Kecil Menengah" Semnas IF2010, 1979-2328.

[3] Keller, Kevin Lane.2003. Strategic Brand Management: Building, Measuring anD Managing Brand Equity. NewJersey: Prentice Hall.

[4] Kusrianto, Adi. 2007. Pengantar Desain Komunikasi Visual.Yogyakarta:ANDI.

[5] Kholil I(2012) “Aplikasi E-CRM Berbasis WEB Dalam Meningkatkan Daya Saing Usaha Kecil Menengah "Vol.3(1) Jurnal Widya Cipta.

[6] Saputra, Defrizal.2011.Video Iklan Layanan Masyarakat Pelatihan Loka Bina Karya Dinas Sosial dan Tenaga Kerja Kota Padang.Padang:UNP.

[7] Sawitri P, Wulandari L, Wayan Simri WI (2012) "Customer Relationship Management (Crm) Untuk Usaha Kecil Dan Menengah” No.Makalah : 136 Konfrensi Nasional Sistem Informasi. 